\title{
PENGGUNAAN TEKNIK PEMBELAJARAN FISHBONE DIAGRAM DALAM MENINGKATKAN KETERAMPILAN MEMBACA SISWA
}

\author{
Christiana Evy Tri Widyahening \\ Fakultas Keguruan dan Ilmu Pendidikan, Universitas Slamet Riyadi \\ E-mail: christiana.widyahening@gmail.com
}

\begin{abstract}
Abstrak
Tujuan dari kajian ini adalah untuk menggambarkan penggunaan dan peran teknik pembelajaran Fishbone Diagram dalam pembelajaran reading skill. Kajian ini menggunakan metode deskriptif kualitatif dengan teknik kajian pustaka. Hasil kajian menggambarkan bahwa bahasa merupakan dasar dari kemampuan yang dimiliki oleh manusia. Sebagai makhluk sosial, manusia membutuhkan bahsa untuk berkomunikasi. Manusia juga membutuhkan bahasa untuk berbagi pendapat, informasi, gagasan dan mengungkapkan perasaan. Teknik diagram Fishbone digunakan untuk menentukan hubungan sebab akibat dalam sebuah gagasan yang kompleks atau peristiwa. Teknik ini dapat membantu siswa untuk memahami bagaimana sebuah tema utama memiliki gagasan yang bermacam-macam dan saling berkaitan. Teknik diagram Fishbone merupakan teknik yang sangat bagus digunakan dalam meningkatkan keterampilan membaca siswa.
\end{abstract}

Kata kunci: Ketrampilan membaca, Fishbone Diagram

THE USE OF FISHBONE DIAGRAM LEARNING TECHNIQUE IN LEARNING READING SKILL

\section{Christiana Evy Tri Widyahening}

Faculty of Education, Universitas Slamet Riyadi

E-mail: christiana.widyahening@gmail.com

\begin{abstract}
This study used qualitative descriptive method with the technique was library study. The result of this study described that language is the basic of humanity. As a social creature, human needs language to communicate each others. Human also extremely needs language to share their opinion, information, ideas, and to express their feelings. Every nation has its own language as a means of communication within its society. One of important language which is used in the world is English. This technique can help students to understand how the central theme has numerous related ideas. Fishbone Diagram technique is a great technique to be used in teaching and learning process of reading skill.
\end{abstract}

Key words: Reading skill, Fishbone Diagram 


\section{PENDAHULUAN}

Bahasa merupakan alat komunikasi yang sangat penting dalam kehidupan manusia. Manusia membutuhkan bahasa untuk berbagi informasi, gagasan, pemikiran, pendapat dan juga mengungkapkan perasaannya terhadap manusia yang lain. Setiap negara memiliki bahasa mereka masing-masing sebagai alat komunikasi antar anggota masyarakatnya. Di dunia ini, terdapat banyak sekali bahasa dan salah satu bahasa yang digunakan di dunia sebagai alat komunikasi adalah bahasa Inggris sebagai salah satu bahasa internasional yang diakui oleh PBB (Persatuan Bangsa-Bangsa).

Bahasa Inggris sangat penting peranannya dalam kehidupan sehari-hari masyarakat dunia karena bahasa tersebut banyak digunakan di berbagai sektor kehidupan, misalnya di media massa, pendidikan, ilmu pengetahuan dan teknologi, politik, sosial budaya, perdagangan, dan masih banyak lagi.

Di Indonesia, bahasa Inggris menjadi bahasa asing pertama yang wajib dipelajari dan dikuasai oleh berbagai pihak khususnya para pelajar. Bahasa Inggris dipelajari oleh pelajar dari tingkat pendidikan anak usia dini sampai pada tingkat universitas. Menyadari akan pentingnya bahasa Inggris, maka pemerintah Indonesia memberikan prioritas terhadap bahasa Inggris sebagai bahasa asing pertama yang wajib diajarkan di Indonesia. Berdasarkan Kurikulum Tingkat Satuan Pendidikan (KTSP 2006) menyebutkan bahwa Pembelajaran bahasa Inggris di Sekolah Menengah harus menekankan pada empat ketrampilan berbahasa yaitu mendengarkan (listening), berbicara (speaking), membaca (reading), dan menulis (writing). Penekanan tersebut diharapkan agar siswa dapat mengasah dan menggunakan ketrampilan berbahasa Inggris mereka dengan baik guna mempersiapkan diri mereka ke tingkat pendidikan yang lebih tinggi dan juga dalam mencari lapangan pekerjaan.

Ada 4 ketrampilan berbahasa dalam mempelajari bahasa Inggris yaitu mendengarkan (listening), berbicara (speaking), membaca (reading), dan menulis (writing). Salah satu ketrampilan berbahasa yang wajib dipelajari dan dikuasai oleh siswa adalah Reading Skill. Menurut Urquhart dan Weir (dalam Grabe, 2009) reading is process of receiving and interpreting information encoded in language from via the medium of print. Artinya bahwa informasi diperoleh sesudah proses membaca.

Proses belajar mengajar Reading skill tidak selalu membuat siswa merasa nyaman dan senang untuk mengikuti proses belajar mengajar tersebut. Hal tersebut dikarenakan oleh ketidakmampuan siswa dalam memahami 
teks berbahasa Inggris. Ketidakmampuan tersebut menjadi suatu hambatan yang berdampak terhadap banyak hal, antara lain mudah merasa bosan manakala proses belajar mengajar Reading skill berlangsung, kurangnya perbendaharaan kata dalam bahasa Inggris, terlalu pasif dalam proses belajar mengajar, kurangnya motivasi dalam proses belajar mengajar Reading skill. Hambatan lain yang menghambat proses belajar mengajar Reading skill dapat berasal dari guru, yaitu antara lain guru masih mengajar dengan cara berpusat pada dirinya dalam proses belajar mengajar atau Teacher Centered Learning, guru juga masih menerjemahkan tiap kalimat dari suatu teks berbahasa Inggris secara langsung sehingga hal tersebut menjadi terasa membosankan dan membuat siswa cenderung pasif, terkadang dijumpai masih banyak guru yang tidak menggunakan teknik pembelajaran ataupun media pembelajaran yang inovatif dalam proses belajar mengajar. Padahal, penggunaan teknik pembelajaran dan media pembelajaran yang inovatif sangat penting dalam meningkatkan ketrampilan berbahasa dan dapat memotivasi belajar siswa bila diterapkan dengan baik dan benar. Perlu kesungguhan guru pula dalam menggunakan teknik pembelajaran dan media pembelajaran yang inovatif sehingga dapat terlaksana proses belajar mengajar yang baik dan berhasil. Salah satu teknik pembelajaran inovatif yang dapat digunakan adalah teknik Fishbone Diagram. Fishbone Diagram merupakan teknik pembelajaran yang diperkenalkan pertama kali oleh Kaoru Ishikawa (19151989). Penggunaan teknik Fishbone Diagram dalam proses belajar mengajar adalah untuk menentukan hubungan sebab akibat dalam sebuah gagasan atau peristiwa yang kompleks. Teknik ini dapat membantu siswa dalam memahami bagaimana sebuah tema utama dapat memiliki gagasan yang beraneka macam dan saling berkaitan satu sama lain. Teknik Fishbone Diagram merupakan teknik pembelajaran yang baik digunakan dalam proses belajar mengajar Reading skill karena teknik ini dapat disesuaikan dengn kondisi dan karakteristik siswa.

\section{KAJIAN PUSTAKA}

\section{Keterampilan Membaca (Reading Skill)}

Membaca merupakan sebuah kegiatan yang melibatkan sebuah proses menerima dan menerjemahkan sebuah informasi yang terjadi di dalam otak. Seperti yang dikemukakan oleh Breznitz (dalam Grabe, 2009) yang menyatakan bahwa reading is an interactive process in two ways. Lebih lanjut, Nunan (1989) menambahkan bahwa reading is an interactive process between what a reader already knows about a given topic or subject and what the writer writes. Proses 
belajar mengajar membaca sangat penting karena di dalam pembelajaran tersebut guru dituntut untuk mampu mengajar dan membangun pengetahuan siswa dengan aktivitas membaca khususnya membaca teks berbahasa Inggris. Pengajaran sendiri, menurut Brown (2007) memiliki arti yaitu guiding and facilitating learning, enabling the learner to learn, setting the condition for learning. Jadi, pengajaran merupakan sebuah proses dalam membantu dan memfasilitasi serta membimbing siswa untuk belajar dan mengembangkan pengetahuannya.

Proses belajar mengajar membaca tidak hanya dimaksudnya dengan sekedar memberi sebuah teks berbahasa Inggris saja kepada siswa melainkan juga terdapat unsur-unsur dalam mengembangkan kesadaran mereka tentang pentingnya membaca dan memahami isi bacaan dengan baik dan benar. Belajar membaca khususnya membaca teks bahasa Inggris memang memerlukan perhatian ekstra karena membutuhkan waktu yang cukup banyak, penguasaan kosa kata bahasa Inggris yang tidak sedikit, dan juga memahami komponen-komponen yang ada dalam proses membaca, seperti Phonemic Awareness, Phonic, Fluency, Vocabulary, dan Comprehension. Tidak sedikit siswa yang memiliki motivasi rendah dalam membaca teks bahasa Inggris yang disebabkan oleh ketidaktersediaan media belajar yang layak di tiap kelas, guru yang tidak menggunakan teknik pembelajaran yang sesuai dalam memaparkan dan membimbing siswa memahami materi pembelajaran membaca.

Guru bahasa Inggris yang profesional cenderung memiliki perspektif yang lebih maju, memiliki pengetahuan tentang media dan teknik pembelajaran inovatif yang baik serta dapat menerapkan dan menggunakannya di dalam proses belajar mengajar dengan baik dan benar pula. Menurut Brown (2000) ada 3 bagian yang perlu diperhatikan dalam proses belajar mengajar membaca, antara lain 1) before you read: spend some time introducing a topic, encouraging skimming, scanning, predicting and activating schemata. Students can bring the best of their knowledge and skills to a text when they have been given a chance to 'ease into' the passage; 2) while-read: not all reading is simply extensive or global reading. There may be certain facts or rhetorical devices that the students should take note while they read. Give the students a sense of purpose for reading rather than just reading because you ordered it; and 3) after you read: comprehension questions are just one form of activity appropriate for post-reading. Also consider vocabulary study, identifying the author's purpose, discussing the author's line of reasoning, examining grammatical structures, or 
steering students toward a follow up writing exercises. Dengan memperhatikan 3 hal tersebut di atas, dapat dimungkinkan proses belajar mengajar membaca teks berbahasa Inggris dapat berjalan dengan baik dan lancar. Hal tersebut pastilah juga ditunjang dengan penggunaan teknik pembelajaran yang sesuai dengan karakteristik siswa, seperti contohnya dengan penggunaan teknik Fishbone Diagram.

\section{Teknik Fishbone Diagram}

Fishbone Diagram (dikenal juga dengan sebutan the Cause and Effect Diagram atau Ishikawa Diagram) diperkenalkan pertama kali oleh pencetusnya yaitu Kaoru Ishikawa (19151989), seorang warga negara Jepang. Menurut Kang dan Kvam (2011) Fishbone Diagram adalah an illustration that is used to explore potential or real causes of quality problem. Ishikawa (dalam Juran, 1999) menambahkan bahwa Diagram Fishbone adalah to organise and display the interrelationships of various theories of root cause of a problem. Sedangkan Doty (1996) memaparkan bahwa Diagram Fishbone adalah just a group of causes and effects diagrammed to show the interrelationship.

Ada beberapa fungsi dasar dari Fishbone Diagram yaitu 1) mengkategorikan berbagai sebab potensial dari suatu masalah atau pokok persoalan dengan cara yang rapi; 2) menganalisis tentang apa yang sesungguhnya terjadi dalam suatu proses; 3) mengajarkan kepada tim dan individu tentang proses serta prosedur saat ini atau yang baru (Chang dan Niedzwiecki dalam Nurson, 1993). Fishbone Diagram dapat digunakan untuk mengidentifikasi dan mengorganisir sebab-sebab yang mungkin muncul dari efek-efek khusus. Kemudian memisahkan akar penyebabnya dan menyebutkan beberapa permasalahan yang muncul. Setiap siswa yang terlibat dalam kegiatan dengan menggunakan teknik ini dapat memberikan kontribusinya dengan cara memberi masukan atau petunjuk yang mungkin saja menjadi penyebab dari permasalahan yang muncul.

Melalui teknik Fishbone Diagram ini, guru dapat membantu siswa dalam menangkap konsep abstrak dari sebuah ide pokok suatu teks berbahasa Inggris. Teknik ini juga memiliki keunggulan bila diterapkan yaitu 1) dapat membatu siswa dan guru dalam mencari akar sebab dan mengidentifikasi wilayah yang mana memiliki permasalahan yang saling berhubungan (Kang dan Kvam, 2011); 2) dapat membantu siswa mengorganisir dan menghubungkan teks secara detil sehingga mereka dapat mengidentifikasi ide pokok dalam teks yang berupa informasi (McKnight, 2013); 3) dapat membantu siswa untuk memahami bagaimana sebuah 
tema pokok dapat memiliki gagasangagasan yang beraneka macam dan saling berhubungan (McKnight, 2010).

\section{Meningkatkan Keterampilan Membaca}

\section{(Reading Skill) dengan Fishbone}

\section{Diagram}

Di dalam proses belajar mengajar, guru membutuhkan teknik pembelajaran yang sesuai dengan karakteristik siswa dan materi pembelajaran yang hendak diajarkan. Hal tersebut penting untuk diperhatikan karena menjadi salah satu faktor yang dapat meningkatkan kualitas proses belajar mengajar itu sendiri. Dengan menggunakan teknik pembelajaran yang tepat, guru dapat menentukan perlakuan bagi siswanya sesuai dengan karakteristiknya sebelum melaksanakan proses belajar mengajar agar memperoleh hasil yang memuaskan di akhir pembelajaran.

Terdapat banyak sekali teknik pembelajaran yang inovatif yang dapat digunakan dalam proses belajar mengajar membaca. Tentunya, teknik pembelajaran tersebut memiliki kelebihan dan kelemahan. Teknik pembelajaran yang digunakan dalam proses belajar mengajar membaca haruslah yang sesuai dan tepat dengan materi belajar dan juga cocok dengan karakteristik siswa. Teknik pembelajaran yang baik adalah teknik yang mampu menstimulasi keaktifan siswa dalam proses belajar mengajar sehingga mereka dapat meningkatkan, mengkomunikasikan, dan menguraikan gagasan-gagasan mereka dengan baik seusai membaca sebuah teks bacaan.

Salah satu teknik yang dapat digunakan dalam proses belajar mengajar membaca adalah teknik Fishbone Diagram. Merujuk pada pendapat Ishikawa (dalam Juran, 1999) bahwa Fishbone Diagram Technique is to organize and display the interrelationships of various theories of root cause of a problem. Jadi, teknik Diagram Fishbone dapat membantu siswa dalam mengkomunikasikan penyebab-penyebab potensial yang berbeda dari sebuah permasalahan yang khusus atau efek-efek yang berasal dari sumber-sumber yang berlainan. Di dalam tahap pemanasan pada proses belajar mengajar, bagian dari Diagram Fishbone yang berupa cabangcabangnya dapat dengan mudah ditambahkan atau dihilangkan tergantung dari pemecahan masalahnya.

Teknik Diagram Fishbone mengharuskan guru untuk membimbing siswa dalam proses belajar mengajar. Guru membimbing siswa tentang tahapan kegiatan, menjelaskan tentang informasi penting yang terdapat di dalam teks bacaan, mengumpan gagasan siswa dan membantu mereka untuk mencari informasi khusus dari sebuah alur kejadian 
serta menjawab pertanyaan sulit yang diajukan oleh siswa.

Terdapat beberapa tahapan dalam menerapkan teknik Diagram Fishbone kedalam proses belajar mengajar membaca ini, yaitu 1) menentukan karakteristik mutu; 2) menuliskan karakteristik mutu pada diagram Fishbone; 3) menuliskan faktor-faktor penyebab utama; 4) menentukan item-item yang penting dari setiap faktor; dan 5) gunakan pertanyaanpertanyaan untuk mengetahui faktor-faktor penyebab (Ishikawa dalam Widodo, 1989).

Di dalam penerapannya, guru perlu menjelaskan terlebih dahulu kepada siswa tentang apa yang dimaksud dengan teknik pembelajaran diagram tulang ikan atau Fishbone,gambar dari diagram Fishbone, contoh penggunaan diagram Fishbone, manfaat dari teknik tersebut dalam proses belajar mengajar membaca, dan cara menggunakan teknik diagram Fishbone dalam proses belajar mengajar membaca. Setelah penjelasan tersebut, siswa dapat memulai untuk menggunakan diagram Fishbone dari menggambar diagram Fishbone dan menentukan gagasan utama dari teks bacaan yang diberikan oleh guru kemudian menuliskan gagasan utama pada kepala ikan, menentukan faktor-faktor utama pada tulang ikan yang diambil dari teks bacaan yang diberikan oleh guru, dan menentukan butir-butir penting lainnya di masing-masing faktor. Tugas ini dapat dilaksanakan oleh siswa dengan membentuk kelompok yang terdiri dari 4-5 siswa di masing-masing kelompok. Guru bertugas membimbing siswa untuk melakukan diskusi tentang nilai-nilai moral yang terkandung di dalam teks bacaan apabila teks bacaan tersebut berupa teks narasi dengan menggunakan diagram Fishbone.

Teknik pembelajaran Diagram Fishbone sesuai bila diterapkan dalam proses belajar mengajar membaca berbahasa Inggris. Banyak hal yang bisa diperoleh dengan adanya penerapan teknik ini kedalam proses belajar mengajar membaca, antara lain 1) situasi kelas menjadi nyaman dan adanya suasana pembelajaran yang aktif, kelas menjadi hidup selama proses belajar mengajar berlangsung; 2) siswa menjadi lebih antusias, aktif dan percaya diri. Kegiatan belajar mengajar berpusat pada siswa; 3) siswa diajarkan untuk berani mengemukakan pendapat dalam bentuk diskusi kelompok dan diskusi kelas yang membahas mengenai teks bacaan dengan menggunakan diagram Fishbone. Siswa semakin termotivasi dalam belajar bahasa Inggris khususnya membaca teks bahasa Inggris; 4) siswa tidak mudah merasa bosan selama proses belajar mengajar membaca karena aktivitas belajar mengajar berpusat pada siswa; dan 5) siswa mengerjakan tugasnya dengan percaya diri 
tanpa takut untuk merasa melakukan kesalahan dalam mengerjakan tugas.

\section{KESIMPULAN DAN SARAN}

Proses belajar mengajar membaca atau Reading skill dengan menggunakan teknik Diagram Fishbone dapat memperbaiki kualitas hasil pembelajaran siswa. Siswa dapat dengan mudah menemukan gagasan utama, menentukan kata ganti orang, memperbanyak kosa kata, dan memperoleh informasi yang implisit maupun eksplisit dari sebuah teks bacaan.

Diagram Fishbone menciptakan sebuah suasana yang nyaman, santai, aktif namun serius dalam proses belajar mengajar. Suasana tersebut dapat membuat siswa dengan penuh percaya diri turut terlibat secara aktif dalam kegiatan diskusi kelompok maupun diskusi kelas untuk membahas teks bacaan yang diberikan oleh guru. Mereka menjadi lebih aktif dan bersemangat dalam kegiatan membaca serta antusias mengikuti proses belajar mengajar, percaya diri dalam berbagi gagasan dengan seluruh isi kelas dan meningkatkan pula rasa saling menghargai di antara siswa. Siswa juga belajar untuk mendengarkan gagasan rekan sejawatnya dan memberi respon yang membangun terhadap gagasan tersebut. Situasi dalam proses belajar mengajar tersebut dilaksanakan dengan cara bekerjasama dalam kelompok, mendiskusikan hasil atau jawaban dari pertanyaan yang diajukan oleh rekan sejawatnya yang lain dan membagi hasil bahasannya kepada seluruh isi kelas.

Melalui teknik ini siswa juga dilatih untuk memupuk rasa saling kerjasama yang baik antar rekan sejawat. Teknik Diagram Fishbone tersebut bila diterapkan dengan baik dan benar memang akan memiliki dampak yang sangat signifikan dalam tercapainya proses belajar mengajar menjadi lebih baik. Oleh sebab itu, teknik ini sangat disarankan untuk diterapkan dalam proses belajar mengajar bahasa Inggris khususnya dalam hal pembelajaran ketrampilan membaca karena mampu memupuk rasa kerjasama, keaktifan siswa dalam berdiskusi, membangun rasa percaya diri dan juga membiasakan suatu pola students-centered learning dalam proses belajar mengajar. Teknik ini dapat berjalan dengan baik apabila juga didukung oleh semua pihak khususnya guru yang mampu dan menguasai teknik pembelajaran ini sehingga dapat diterapkan dengan baik dalam proses belajar mengajar di kelas.

\section{DAFTAR PUSTAKA}

Brown, H. Douglas. 2000. Teaching by Principles: An Interactive Approach to Language Pedagogy. London: Longman. 2007. Principles of Language Learning and Teaching. Fifth Edition. San Fransisco: Longman. 
Doty, Leonard .A. 1996. Statistical Process Control. Second Edition. New York: Industrial Press.

Grabe, William. 2009. Reading in a Second Language: Moving from Theory to Practice. Cambridge: Cambridge University Press.

Juran, M. Joseph dan A. Blanton Godefrey. 1999. Juran's Quality Handbook. Washington: McGraw-Hill.

Kang, Chang W dan Paul H Kvam. 2011. Basic Statistical Tools for Improving Quality. New Jersey: Hoboken.
McKnight, Katherine S. 2010. The Teacher's Big Book of Graphic Organizers. San Fransisco: Jossey-Bass.

Nunan, David. 1989. Designing Task for the Communicative Classroom. Cambridge: Cambridge University Press.

Nurson, Erlinda M. 1993. Alat Peningkatan Mutu: Jilid 1. Jakarta: PT. Pustaka Binaman Pressindo.

Widodo, Nawolo. 1989. Teknik Penuntun Pengendali Mutu. Jakarta: Mediyatama Sarana Perkasa. 